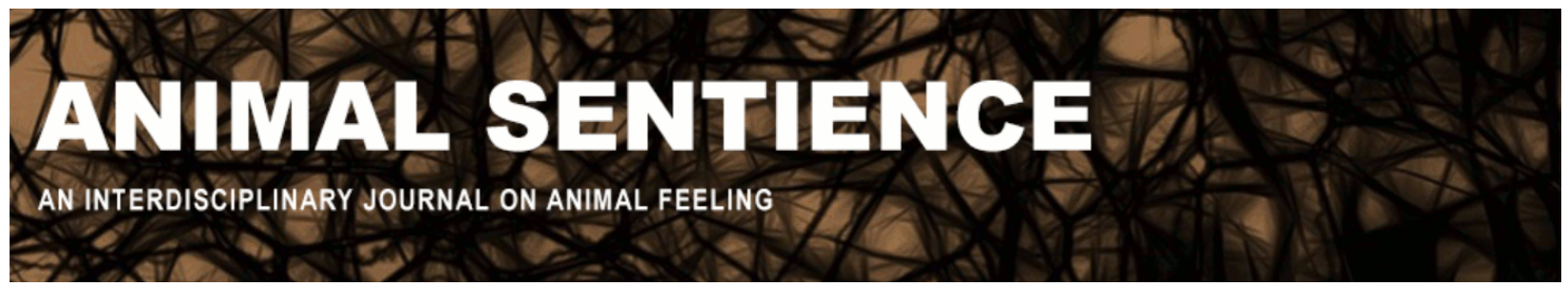

Lee, Andrew Y. (2020) Does sentience come in degrees?. Animal Sentience 29(20)

DOI: $10.51291 / 2377-7478.1607$

Date of submission: 2020-06-30

Date of acceptance: 2020-07-03

(c)

This article has appeared in the journal Animal

Sentience, a peer-reviewed journal on animal

cognition and feeling. It has been made open access,

free for all, by WellBeing International and deposited

in the WBI Studies Repository. For more information,

please contact

wbisr-info@wellbeingintl.org.

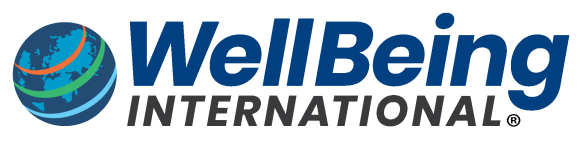

SOLUTIONS FOR PEOPLE, ANIMALS AND ENVIRONMENT 


\title{
Does sentience come in degrees?
}

Commentary on Mikhalevich \& Powell on Invertebrate Minds

\author{
Andrew Y. Lee \\ School of Philosophy, Australian National University
}

\begin{abstract}
consciousness," comes in degrees.
Andrew Y. Lee is a Postdoctoral Research Fellow in Philosophy at Australian National University. His research is on philosophical questions about the structure, ethics, and epistemology of consciousness. Website
\end{abstract}

Abstract: This commentary is about whether sentience, or what philosophers call "phenomenal

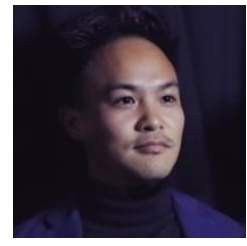

Mikhalevich \& Powell (2020) (M\&P) provide a wide-ranging and commendable discussion of some empirical and philosophical questions about invertebrate minds. My commentary addresses a question that M\&P mention in passing but that is worth thinking about more carefully: does sentience come in degrees? This question is particularly interesting in the present context: if arthropods are sentient, we might wonder whether some arthropods (such as ants) are in some sense less sentient than other organisms (such as humans).

Following this journal's terminological guidelines, I use "sentience" to mean what philosophers call "phenomenal consciousness." An organism is phenomenally conscious if there is something it is like to be that organism. It is obvious that the capacity for sentience comes in degrees. But does sentience itself come in degrees? Can we meaningfully say that one sentient organism is more sentient than another sentient organism?

The relevant passage from $M \& P(p .8)$ asks whether sentience "is a discrete, rather than continuous property." M\&P say the latter would mean that sentience is "continuously distributed in the animal world with no clear cutoff between experiencers and those that are incapable of experience." They state that the key issue concerns "what the lowest bounds of this spectrum might look like." Speaking metaphorically, the question is whether "the lights are either on or off" or whether there might also be a "dimmer switch." I think these remarks actually contain three distinct questions:

Q1. Is sentience all-or-nothing or a matter of degree?

Q2. Is sentience discrete or continuous?

Q3. Is the concept of sentience vague or sharp?

From the context, I think it is clear that the main issue for M\&P concerns Q1. But some of their remarks are also naturally read as asking Q2 or Q3. Let's begin with why these questions are distinct from one another.

Q1 asks whether sentience is all-or-nothing or a matter of degree. In other words, are some organisms more sentient than other organisms? The metaphor of light is illustrative here: If sentience is all-or-nothing, then the lights are either on or off; but if sentience comes in degrees, then the light can shine at varying levels of brightness. If the latter view is correct, then it is natural 
to ask what exactly would make an organism more or less sentient. We will return to this question in a moment.

Q2 asks whether sentience is discrete or continuous. At first, this may strike some as equivalent to Q1. But taking sentience to admit of degrees is compatible with taking sentience to be either discrete or continuous. Imagine a light switch with a continuous dimmer versus a light switch whose dimmer has ten discrete brightness values ranging from very dim to very bright. Both switches generate differing degrees of light, but the former is continuous while the latter is discrete. In brief: to be all-or-nothing is to have only two possible magnitudes, on or off; to be degreed is to have many possible magnitudes; to be continuous is to have a continuum of magnitudes; to be discrete is to be not continuous. Given this, Q2 arises only if we have already answered "yes" to Q1.

Q3 asks whether the concept of sentience is vague or sharp. In other words, are there organisms for whom there is no determinate fact about whether they are sentient or not? This question about vagueness is independent of the question about degrees, since whether the concept of sentience is vague leaves open whether some organisms are more sentient than others. As an analogy, consider how both the concepts of "tall" and "scientist" are vague, but the former is a matter of degree (one person can be taller than another) while the latter is all-ornothing (one person cannot be "more scientist" than another). On the other hand, it is hard to understand what it would mean for there to be indeterminate cases of sentience: even if there is barely something it feels like to be an organism, that organism would still count as sentient (Simon, 2017). This suggests that the concept of sentience is sharp: the lights are either on or off, and even the dimmest light counts.

Let's return now to $\mathrm{Q} 1$. In what sense might some organisms be more sentient than others? There are plenty of aspects of sentience that come in degrees: for example, the intensity, duration, complexity, or precision of an experience; the number of qualitatively distinct experiences an organism is able to have; or the degree to which information about a sentient experience is accessible for cognition (Pautz, 2019). But do any of these give us reason for saying that sentience itself comes in degrees? It seems to me that the key question is whether we can make sense of greater or lesser quantities of sentience, in the same way that we can make sense of greater or lesser quantities of light. However, that question depends on unresolved questions about how conscious experiences are structured. Given this, I think it is better simply to talk about each of the aforementioned aspects directly rather than to invoke the nebulous notion of "degree of sentience" (Bayne, Hohwy, \& Owen 2016). In light of this, I think it is best to avoid talk of degrees of sentience, at least until we have a better understanding of what that might mean.

\section{References}

Bayne, T., Hohwy, J. \& Owen, A. M. (2016). Are there levels of consciousness? Trends in Cognitive Sciences 20 (6):405-413.

Mikhalevich, I. \& Powell, R. (2020). Minds without spines: Evolutionarily inclusive animal ethics. Animal Sentience 29(1).

Pautz, A. (2019). What is the Integrated Information Theory of Consciousness? Journal of Consciousness Studies $26(1-2): 1-2$.

Simon, J. (2017). Vagueness and zombies: Why 'phenomenally conscious' has no borderline cases. Philosophical Studies 174 (8):2105-2123. 